\title{
Physico-mechanical assessment of plaster of Paris bandage produced from locally sourced materials
}

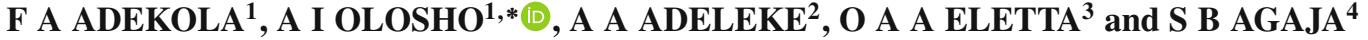 \\ ${ }^{1}$ Department of Industrial Chemistry, University of Ilorin, Ilorin 240003, Nigeria \\ ${ }^{2}$ Department of Mechanical Engineering, University of Ilorin, Ilorin 240003, Nigeria \\ ${ }^{3}$ Department of Chemical Engineering, University of Ilorin, Ilorin 240003, Nigeria \\ ${ }^{4}$ Department of Orthopaedic Surgery, University of Ilorin, Ilorin 240003, Nigeria \\ *Author for correspondence (adebayoolosho@gmail.com)
}

MS received 15 March 2018; accepted 16 August 2018; published online 6 March 2019

\begin{abstract}
Despite the abundance of gypsum and other materials needed for the production of plaster of Paris (POP) in the country, Nigeria relies heavily on the importation of orthopaedic POP bandage. Therefore, the present study aimed at producing POP bandage (LPOP) from locally sourced pure gypsum and cassava starch. Physico-chemical parameters, such as amylose content, amylopectin content, water absorption capacity (WAC), swelling capacity (SC) and browning-charring temperature $(\mathrm{BCT})$ were obtained for the starch binder. A slurry of pure gypsum powder and $2 \%$ gelatinized starch binder was impregnated on cotton gauze and cured in an oven at $180^{\circ} \mathrm{C}$ for an hour to produce the LPOP. A comparative mechanical test was carried out on the LPOP and a POP bandage (CPOP) acquired from the market using a universal testing machine. The results showed that starch contains $9.06 \mathrm{mg}$ per $100 \mathrm{~g}$ amylose and $24.1 \mathrm{mg}$ per $100 \mathrm{~g}$ amylopectin which implied that it has a good binding property. The SC, WAC and BCT were evaluated to be $69.79,81.94$ and $190^{\circ} \mathrm{C}$, respectively. The yielding tensile force for LPOP and CPOP are 148 and $460 \mathrm{~N}$, respectively. The horizontal compressive strength of the LPOP and CPOP are 1712 and $1595 \mathrm{~N}$ while the vertical compressive strengths are 1070 and $623 \mathrm{~N}$, respectively. These results show that the LPOP produced from locally sourced materials compete favourably in terms of mechanical properties with POP bandage in the market. Thus, based on its strength, it is recommended for orthopaedic casting.
\end{abstract}

Keywords. Gypsum; starch; gelatinization; tensile strength; compressive strength.

\section{Introduction}

Plaster of Paris (POP) orthopaedic bandage is a body cast or surgical cast made from gypsum (calcium sulphate dihydrate) used to hold a broken bone in place for the healing process. It is made up of cotton gauze impregnated with POP (calcium sulphate hemihydrate) with the aid of a binder. This is based on the fact that gypsum loses one-third of its water on crystallization at temperature between 120 and $200^{\circ} \mathrm{C}$ to form hemihydrates $\left(\mathrm{CaSO}_{4} \cdot 0.5 \mathrm{H}_{2} \mathrm{O}\right)$ and re-hydrates back to gypsum in the presence of water to form a hard cast which sets in 5-20 min [1,2].

There is about 1 billion tonnes of gypsum deposits across several states in Nigeria [3], bulk of what is mined is used for cement production and plaster boards [4]. Despite the abundance of gypsum and other material needed for the production of POP in the country, Nigeria relies heavily on the importation of orthopaedic POP bandage. According to Raw Materials Research and Development Council (RMRDC) as reported by Daily Trust, Nigeria has spent about 12.9 billion naira on the importation of plasters in the last 3 years [5].

POP bandage is typically impregnated uniformly onto cotton gauze with the aid of an adhesive such as starch.
The use of starch as adhesive in plaster bandage is well known [6].

Currently, POP bandages and thermoplastic synthetic materials such as fibreglass impregnated with polyurethane are used for orthopaedic cast and splinting. The thermoplastics are lighter and dry much faster than plaster bandages. However, plaster is relatively cheaper, can be more easily moulded, comfortable to fit smoother and does not snag clothing or abrade the skin [7-9]. The porosity of the POP allows absorption, perspiration and prevents skin maceration. It also retains heat, which provides gentle neutral warmth to the body [10-12].

There are several interdependent properties of POP cast that determines its quality. These include particle size of the gypsum, water/powder ratio, Young's modulus and flexural and compressive strengths [13].

Most of the studies available in the literature $[14,15]$ on mechanical properties of orthopaedic casts are comparative studies with casts made from other materials or different manufacturers without any standardization of dimensions [16].

Parmar et al [17] conducted physical and mechanical properties of POP cylindrical cast of two, three and eight 
layers. The POP was formed by wrapping around polyvinyl chloride pipe of $25 \mathrm{~mm}$ in diameter. Axial load was applied at $10 \mathrm{~mm} \min ^{-1}$ on a universal testing machine. The study shows that POP cast with eight layers has the highest value of load-bearing capacity, stress and stiffness followed by two- and three-layer cast. However, these mechanical tests were only carried out along the horizontal axis of the cast. Tensile strength was not reported. Similar studies have also been conducted without distinguishing horizontal and vertical compressive strength of the casts $[15,16,18]$. The availability of the literature on the mechanical properties of casts made from indigenous materials is very scarce.

Therefore, the aim of this study is to produce POP bandage from locally sourced gypsum, starch and cotton gauze. The mechanical assessment of the POP will also be evaluated to establish its suitability for orthopaedic casting in comparison with the available POP bandage in the market.

\section{Experimental}

\subsection{Sample collection and preparation}

Gypsum samples were obtained from a mining site in Potiskum, Yobe state, Nigeria $\left(11.717^{\circ} \mathrm{N}, 11.067^{\circ} \mathrm{E}\right)$. The raw gypsum sample was washed with water while using a wire brush to remove the surface impurities such as clay, and then air-dried [19]. It was thereafter pulverized and sieved into $-90+63 \mu \mathrm{m}$ particle size. The sample was treated with hydrochloric acid to obtain highly pure gypsum [20].

Tropical Manihot Esculenta (TME) 7 cassava variety was obtained from a garri processing factory in Ilorin metropolis $\left(8.4799^{\circ} \mathrm{N}, 4.5418^{\circ} \mathrm{E}\right)$. Starch was extracted from cassava according to the method of Agunbiade and Ighodaro [21]. It was analysed for amylose and amylopectin in accordance with the method of Doue et al [22]. The moisture content was determined by the method described by Oladunmoye et al [23]. Swelling capacity (SC) was evaluated following the method of Olu-Owolabi [24]. Water binding capacity was estimated using the method described by Nuwamanya et al [25]. Each analysis was conducted in duplicate.

Cotton gauze $(14 \mathrm{~cm} \times 4.5 \mathrm{~cm})$ of hospital quality manufactured by Ogotex adsorbent gauze bandage and POP bandage manufactured by Anji Hongde Medical Products Co. Ltd., Zhenjiang Province, China, were obtained from a pharmaceutical store in Ilorin. Casts made from the POP bandage obtained from the market served as a control sample for mechanical assessments.

\subsection{Preparation of $L P O P$ bandage composite}

The Bureau of Indian Standards [26] and Cast Standards of British Orthopaedic Association [27] were used as reference guide in the preparation of the POP bandage from the locally sourced material (LPOP). The present approach is a modification to the existing methods of POP production.
Starch which corresponds to $2 \%$ of gypsum powder was weighed into a beaker and mixed with water. The starch was gelatinized first with water heated to $100^{\circ} \mathrm{C}$ to make a slurry with the gypsum powder. Four hundred grams of gypsumstarch blend per unit area of the gauze was used in preparing the bandage. Cotton gauze was spread on smooth flat surface that is covered with Teflon and the slurry was impregnated on it and allowed to dry. The bandage was lifted after drying and heated in oven at $180^{\circ} \mathrm{C}$ for an hour.

\subsection{Mechanical assessment for POP cast}

LPOP was formed into casts according to the procedure described by Parmar et al [17]. For standardization and consistency, all casts were made by one researcher [16]. The casts were divided into two groups: cylinders and plates simulating clinical applications [15]. The cylindrical casts were formed by wrapping $50 \mathrm{~cm} \times 15 \mathrm{~cm}$ of LPOP and CPOP around a glass rod of $1.2 \mathrm{~cm}$ in diameter and $120 \mathrm{~cm}$ in length. This cylinder group consists of two subgroups each having three samples for vertical and horizontal compressive strength tests (figure $1 \mathrm{~b}$ and c). The plate group consists only of three samples each $15 \mathrm{~cm}$ wide and $20 \mathrm{~cm}$ long LPOP and CPOP bandage folded into three layers along the width to form a cast of $4 \mathrm{~cm}$ wide

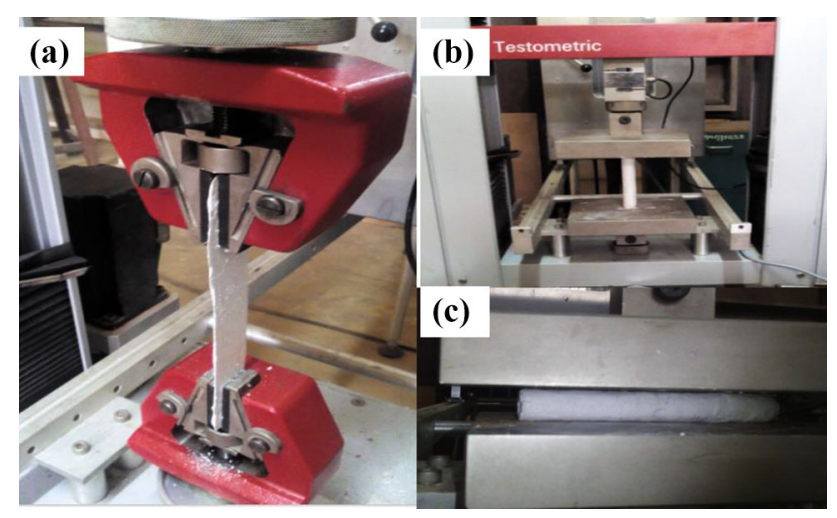

Figure 1. (a) Tensile strength for POP plate cast. (b) Vertical mechanical strength test for cylindrical cast. (c) Horizontal mechanical strength test for cylindrical cast.

Table 1. Physicochemical properties of cassava starch binder.

\begin{tabular}{lr} 
Test & \multicolumn{1}{c}{ Results } \\
\hline Amylose (mg per $100 \mathrm{~g})$ & $9.062 \pm 0.34$ \\
Amylopectin (mg per $100 \mathrm{~g})$ & $24.107 \pm 0.61$ \\
Swelling capacity (SC) at $50^{\circ} \mathrm{C}(\%)$ & $69.785 \pm 0.63$ \\
Water absorption capacity (WAC) $(\%)$ & $81.9485 \pm 0.22$ \\
Foaming capacity (FC) $\left(\mathrm{cm}^{3}\right.$ per $\left.2 \mathrm{~g}\right)$ & $4.55 \pm 0.07$ \\
Solubility index (SI) $(\%)$ & $4.625 \pm 0.02$ \\
Browning and charring temp. $(\mathrm{BCT})\left({ }^{\circ} \mathrm{C}\right)$ & $190 \pm 0$ \\
pH & $6.3 \pm 0.14$ \\
Gelatinization temp. $\left({ }^{\circ} \mathrm{C}\right)$ & $85.9 \pm 0.14$
\end{tabular}




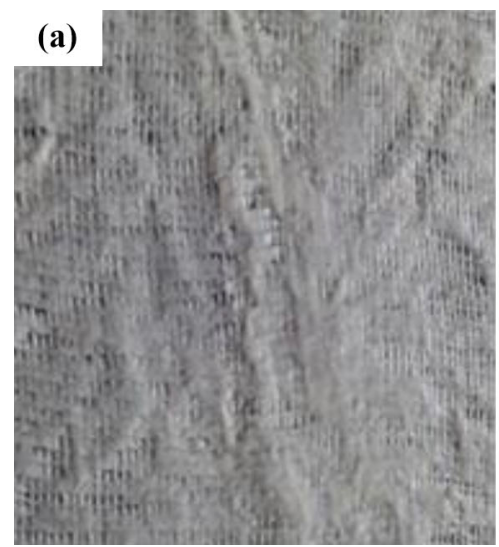

\section{(b)}

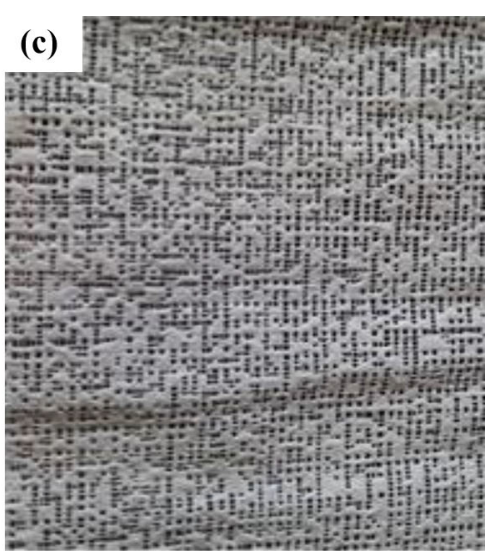

Figure 2. Images of POP bandage: (a) after impregnation, (b) after drying and (c) control POP sample.

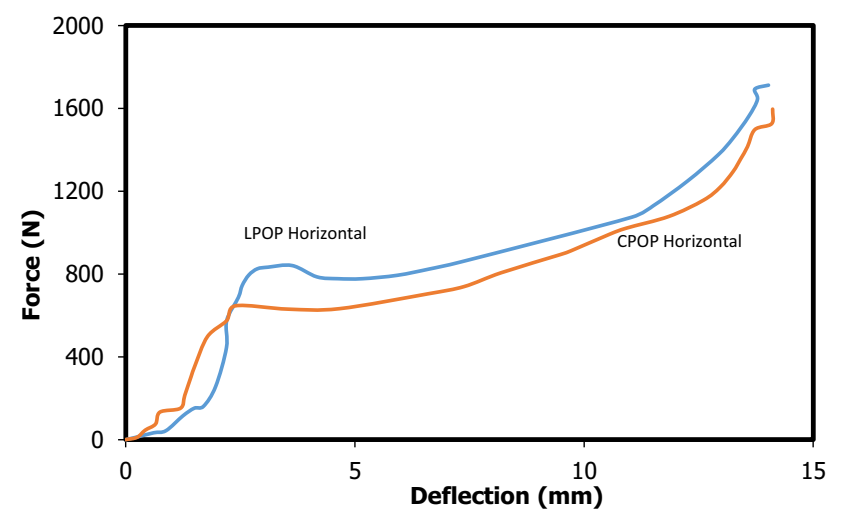

Figure 3. Force-deflection curve of horizontal compressive strength of LPOP and CPOP.

Table 2. Horizontal compressive strength of LPOP and CPOP.

\begin{tabular}{lcc}
\hline & \multicolumn{2}{c}{ Results } \\
\cline { 2 - 3 } Test & LPOP & CPOP \\
\hline Stress at peak $\left(\mathrm{N} \mathrm{mm}^{-2}\right)$ & $0.039 \pm 0.003$ & $0.022 \pm 0.001$ \\
Stress at yield $\left(\mathrm{N} \mathrm{mm}^{-2}\right)$ & $0.015 \pm 0.003$ & $0.01 \pm 0.002$ \\
Strain at break $(\%)$ & $13.990 \pm 2.80$ & $9.624 \pm 0.3$ \\
Young's modulus $\left.(\mathrm{N} \mathrm{mm})^{-2}\right)$ & $1.337 \pm 0.27$ & $1.403 \pm 0.5$ \\
Energy to peak $(\mathrm{N} \mathrm{m})$ & $14.158 \pm 4.00$ & $10.775 \pm 0.6$ \\
Energy to yield $(\mathrm{N} \mathrm{m})$ & $0.649 \pm 0.21$ & $0.620 \pm 0.05$ \\
\hline
\end{tabular}

LPOP, POP prepared from locally sourced materials; CPOP, control POP sample.

and $20 \mathrm{~cm}$ long. The plates were used for tensile strength test (figure 1a). The casts were allowed to fully dry for $72 \mathrm{~h}$ before mechanical assessments. Sample casts were mounted on an FS50AT Testometric Universal Testing Machine and axial load was applied at $10 \mathrm{~mm} \mathrm{~min}^{-1}$ until the failure. Tests were carried out in triplicate and the average is reported. The load-deflection graphs were plotted. The force at yield and at peak before the failure of the casts was recorded. Stress,

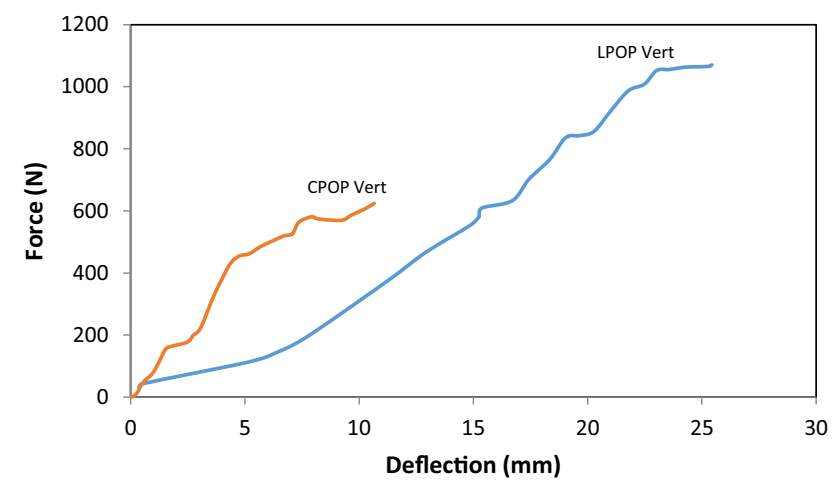

Figure 4. Force-deflection curve of vertical compressive strength of LPOP and CPOP.

Table 3. Vertical compressive strength.

\begin{tabular}{lcl}
\hline \multirow{2}{*}{ Test } & \multicolumn{2}{c}{ Results } \\
\cline { 2 - 3 } & LPOP & \multicolumn{1}{c}{ CPOP } \\
\hline Stress at peak $\left(\mathrm{N} \mathrm{mm}^{-2}\right)$ & $0.010 \pm 0.0009$ & $0.009 \pm 0.001$ \\
Stress at yield $\left(\mathrm{N} \mathrm{mm}^{-2}\right)$ & $0.03 \pm 0.0002$ & $0.002 \pm 0.0002$ \\
Strain at break $(\%)$ & $16.141 \pm 2.15$ & $7.776 \pm 1.93$ \\
Young's modulus $\left(\mathrm{N} \mathrm{mm}^{-2}\right)$ & $0.110 \pm 0.03$ & $0.235 \pm 0.201$ \\
Energy to peak $(\mathrm{N} \mathrm{m})$ & $7.561 \pm 1.308$ & $2.274 \pm 2.15$ \\
Energy to yield $(\mathrm{N} \mathrm{m})$ & $0.571 \pm 0.106$ & $0.140 \pm 0.068$ \\
\hline
\end{tabular}

strain, modulus of elasticity and energy at yield and at peak casts were also reported.

\section{Results and discussion}

\subsection{Physicochemical properties of cassava starch binder}

Results of the several experiments performed to determine the physico-chemical properties of starch used as binding agent 
for the production of POP bandages are shown in table 1 . These results are similar to those reported in earlier studies [24,28,29]. Amylose and amylopectin were found to be 9.06 and $24.11 \mathrm{mg}$ per $100 \mathrm{~g}$ respectively. Amylose is a linear homopolymer of $\alpha-1,4$-linked glucose [30]. In solution, amylose forms hydrogen bonds with other amylase molecules to yield rigid gel, thus making it useful as a thickening, stiffening or gluing agent [31].

Table 4. Tensile strength of LPOP and CPOP.

\begin{tabular}{lcc}
\hline & \multicolumn{2}{c}{ Samples } \\
\cline { 2 - 3 } Mechanical properties & LPOP & CPOP \\
\hline Stress at peak $\left(\mathrm{N} \mathrm{mm}^{-2}\right)$ & $2.006 \pm 0.39$ & $6.223 \pm 0.45$ \\
Stress at yield $\left(\mathrm{N} \mathrm{mm}^{-2}\right)$ & $1.639 \pm 0.57$ & $1.349 \pm 0.144$ \\
Strain at peak (\%) & $1.156 \pm 0.78$ & $5.162 \pm 0.33$ \\
Strain at yield (\%) & $0.080 \pm 0.078$ & $0.302 \pm 0.046$ \\
Young's modulus $\left(\mathrm{N} \mathrm{mm}^{-2}\right)$ & $173.008 \pm 16.58$ & $86.931 \pm 13.25$ \\
Force at peak $(\mathrm{N})$ & $148.467 \pm 28.53$ & $460.467 \pm 33.08$ \\
Force at yield $(\mathrm{N})$ & $75.200 \pm 42.19$ & $132.933 \pm 10.66$ \\
Energy to peak $(\mathrm{N} \mathrm{m})$ & $0.287 \pm 0.25$ & $2.739 \pm 0.17$ \\
\hline
\end{tabular}

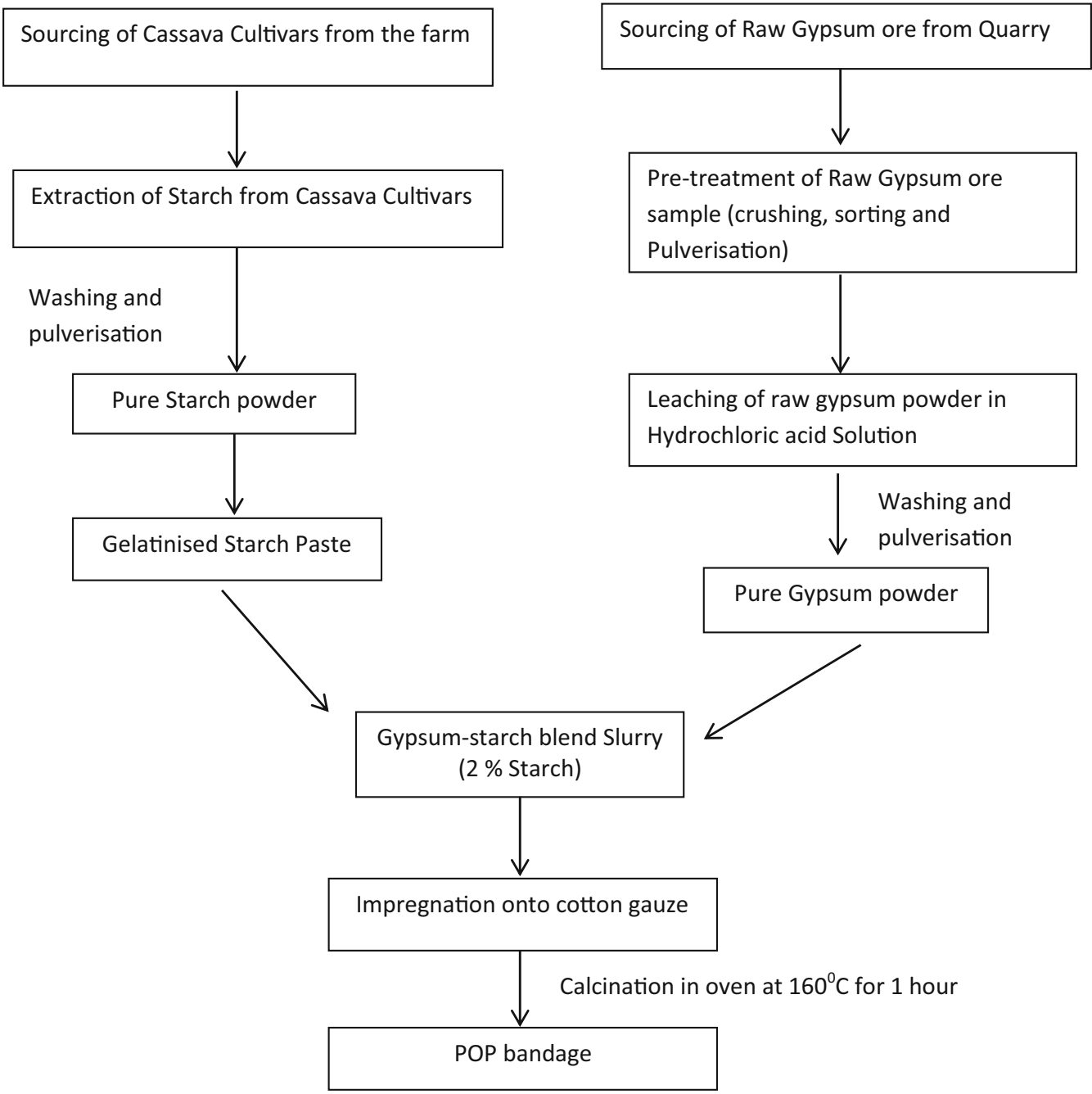

Figure 5. Flow-chart for the production of LPOP. 
Water absorption capacity is the ability of the starch to absorb water and swell for improved consistency. It is also an indication for the presence of amylase which influences the quantity of amylose and amylopectin present. Swelling power is not only a measure of the hydration capacity of the sample, but also indicative of the associative forces in the granules [28]. Doue et al [22] and Sanni et al [32] recommended starch with a similar range of values of SC and solubility index obtained in this study for use as adhesive and paste glue in non-food industries. High SC is a reflection of high associative forces which is desirable as a binding agent [33]. The browning-charring temperature of the starch is $10^{\circ} \mathrm{C}$ higher than the curing temperature. Therefore, its binding ability was not affected during curing.

\subsection{Impregnation of the gypsum-starch composite slurry on cotton gauze}

Figure 2 shows the image of fresh impregnation before and after drying in comparison with the control sample. Compared to the control POP (CPOP) sample, locally produced POP (LPOP) had a fairly uniform overlaid thin film of gypsumstarch composite without any perforations as in the case of CPOP. The perforation may have been adopted for ease of rolling in packaging. However, LPOP performed excellently well when packaged without any crack. It was also observed that the adhesion of plaster on gauze for LPOP is better than CPOP because CPOP plaster removed easily from the gauze than LPOP after drying.

\subsection{Mechanical assessment for POP casts}

The results of the tests performed to determine the capacity of the LPOP and CPOP cylindrical casts to withstand loads along its horizontal axis is presented as a force-deflection in figure 3. LPOP and CPOP exhibit similar resilient behaviour under strain as shown. The failure patterns exhibit a degree of plastic deformation [34] as a result of the presence of cotton gauze that served as the base for impregnation of the POP in preparing the bandage. LPOP and CPOP were eventually failed under compressive deformation at 1712 and $1595 \mathrm{~N}$, respectively. This suggests that LPOP has $7 \%$ extra capacity to bear a compressing force along its horizontal axis than CPOP before failing. The tests also show that stress at peak, stress at yield, energy at peak and energy at yield of LPOP are higher than CPOP as indicated in table 2. The force-deflection curves of the sample casts along the vertical axis however, show brittle deformation patterns to a large extent (figure 4). This is similar to what was reported by Charles and Yen [18]. Permanent deformation of LPOP and CPOP was reached at 1070 and $623 \mathrm{~N}$, respectively. Other parameters, such as force at peak, stress at peak, yield and strain at break are also of higher values for LPOP than CPOP (table 3). The results of the tensile strength in table 4 show that the toughness and stiffness of the control sample (CPOP) are significantly greater than the LPOP. The process of production of LPOP from locally sourced materials developed in the present study is summarized in figure 5.

\section{Conclusions}

The physico-mechanical assessment of POP bandage produced from locally sourced materials has been carried out. The study revealed that the casts produced from the LPOP has better compressive strength of 1092 and $692 \mathrm{~N}$ along the horizontal and vertical axes, respectively, compared to the cast produced from a brand of POP bandage obtained from the market. The flexural strength of the casts produced from LPOP competes favourably with that of POP bandage obtained from the market. Therefore, based on the mechanical assessment, the LPOP bandage is suitable for orthopaedic application.

\section{References}

[1] Anthony J W, Bideaux R A, Bladh K W and Nichols M C (eds) 2003 Gypsum handbook of mineralogy (United States: Mineralogical Society of America)

[2] Brown S A, Radja F E, Kane S M, Siegall E and Wright K 2015 (eds) Orthopaedic immobilization techniques: a step-bystep guide for casting and splinting (United States: Sagamore)

[3] Gyang J D, Nanle N and Chollom S G 2010 Con. J. Sustain. Dev. 123

[4] Lar U A 2006 Proceedings of Nigerian society of chemical engineers conference

[5] Daily Trust. Nigeria Imported 20 bn worth of gypsum in 3 years. https://www.dailytrust.com.ng/index.php/business/263 18-imported-n20bn-worth-of-gypsum-in-3-years (accessed on 21 November 2015)

[6] Ebnezar J 2010 (eds) Essentials of orthopaedics for physiotherapist (India: Jaypee Brothers Medical)

[7] Adkins L M 1997 J. Pediatr. Nurs. 23422

[8] Salter M I and Cheshire L (eds) 2000 Hand therapy, principles and practice (Oxford: Butterworth Heinemann)

[9] Bell-Krotoski J A and Figarola J H 1995 J. Hand Ther. 8131

[10] Law M, Cadman D, Rosenbaum P, Walter S, Russell D and Dematteo C 1991 J. Dev. Med. Child Neurol. 33379

[11] Flatt A E (eds) 1995 The care of the arthritic hand (St. Louis, USA: Quality Medical)

[12] Colditz J C 2002 J. Hand Ther. 15144

[13] Padevět P P and Tesárek T P 2011 Int. J. Mech. 51

[14] Wytch R, Ross N and Wardlaw D 1992 Injury 23101

[15] Vieira G C, Barbosa R I, Marcolino A M, Shimano A C, Elui V M C and Fonseca M C R 2011 Rev. Bras. Fisioter 155

[16] Vieira G C, Fonseca M R, Shimano A C, Nilton M, Cláudio H B and Elui V C M 2006 Acta Orthop. Bras. 143

[17] Parmar A J, Tyagi S K, Dabas V S, Mistry J N, Jhala S K, Suthar D N et al 2014 Vet. World 71123

[18] Charles M N and Yen D 2000 Can. J. Surg. 43365

[19] Irabor P S A, Jimoh S O, Omowumi O J, Ighalo B S O 2013 Int. J. Sci. Technol. Res. 2229

[20] Olosho A I 2016 MSc Thesis (Ilorin: University of Ilorin)

[21] Agunbiade S O and Ighodaro O M 2010 N. Y. Sci. J. 348 
[22] Doue G G, Megnanou R, Bedikou E M and Niamke L S 2014 J. Appl. Biosci. 736002

[23] Oladunmoye O O, Aworh O C, Maziya-Dixon B, Erukainure O L and Elemo G N 2014 J. Food Sci. Nutr. 2132

[24] Olu-Owolabi B I, Olayinka O O, Adegbemile A A and Adebowale K O 2014 Food Nutr. Sci. 5222

[25] Nuwamanya E, Baguma Y, Wembabazi E and Rubailhayo P 2011 Afr. J. Biotechnol. 1012018

[26] Indian Standards (IS) 47381998 (eds) Bandage, plaster of Paris specification (India: Bureau of Indian Standards)

[27] Sue M and Marion W 2015 (eds) Casting standards (United Kingdom: British Orthopaedic Association)

[28] Manek R V, Philip F B, William M K, Martins E and Olobayo O K 2012 AAPS PharmSciTech 13139
[29] Kusumayanti H, Noer A H and Herry S 2015 Proc. Environ. Sci. 23164

[30] Brown W H and Poon T 2005 (eds) Introduction to organic chemistry (United States: Wiley)

[31] Lovegrove A, Edwards C H, De Noni I, Patel H E, Grassby T, Zielke C et al 2017 Crit. Rev. Food Sci. Nutr. 57 237

[32] Sanni L, Maziya-Dixon B, Patino M, Akoroda M, Ezedinma C, Okechukwu R et al 2005 African crop science conference proceedings $\mathrm{p} 583$

[33] Adejumo A L, Aderibigbe A F and Layokun S K $2011 \mathrm{~J}$. Adv. Food Energy Secur. 28

[34] Ajala L, Otutu O L and Bamgbose A 2012 Am. J. Food Nutr. 2 31 